\title{
The occurrence of disinfectant and antibiotic-resistant genes in Escherichia coli isolated from chickens in Egypt
}

\author{
Waleed A. Ibrahim¹, Sherif A. Marouf², Ahmed M. Erfan ${ }^{1}$, Soad A. Nasef ${ }^{1}$ and Jakeen K. El Jakee ${ }^{2}$
}

1. Reference Laboratory for Veterinary Quality Control on Poultry Production, Animal Health Research Institute, P.O. Box 264-Dokki, Giza 12618, Egypt; 2. Department of Microbiology, Faculty of Veterinary Medicine, Cairo University, Giza, Egypt. Corresponding author: Waleed A. Ibrahim, e-mail: waleed.abdelfattah@yahoo.com

Co-authors: SAM: drsherif_marouf@yahoo.com,AME: ahmed.erfan10000@gmail.com, SAN: dr_soadnasef@yahoo.com, JKE: eljakee@cu.edu.eg

Received: 01-10-2018, Accepted: 10-12-2018, Published online: 25-01-2019

doi: 10.14202/vetworld.2019.141-145 How to cite this article: Ibrahim WA, Marouf SA, Erfan AM, Nasef SA, El Jakee JK (2019) The occurrence of disinfectant and antibiotic-resistant genes in Escherichia coli isolated from chickens in Egypt, Veterinary World, 12(1): 141-145.

\begin{abstract}
Aim: This work aimed to determine the occurrence of antibiotic and disinfectant resistance genes in Escherichia coli isolated from chickens in Egypt.

Materials and Methods: Organs (liver, lung, heart, yolk sac, and bone marrow) of 1500 chicken samples were collected from diseased chickens suffered from colibacillosis with PM findings as CRD, diarrhea and omphalitis from different governorates of Egypt as: Giza, EL-Bahira, Fayoum, El-Dakahlia, El-Ismalia, and El-Sharkia during 2015-2016. These samples were labeled and transported immediately on ice to the Reference laboratory for quality control on poultry production (RLQP). The samples were cultured onto MacConkey agar and Eosin Methylene Blue Agar. Isolation and identification of the $E$. coli were performed based on morphology, cultural, staining, and biochemical properties. Antimicrobial resistance test was carried out using disk diffusion method. The PCR employing tetA, qacED1 and qacA/B were carried out for detection of these genes in isolated E.coli.
\end{abstract}

Results: The prevalence of $E$. coli in chicken was 34\%. Predominant serotypes of $E$. coli which serologically identified were $\mathrm{O} 128, \mathrm{O} 111, \mathrm{O} 44, \mathrm{O} 158$, and $\mathrm{O} 2$. Antibiotic susceptibility test of E. coli revealed that $100 \%$ of isolates were resistant to ampicillin, erythromycin, and sulfamethoxazole-trimethoprim, while $73.53 \%$ and $38.23 \%$ of them were sensitive for colistin sulfate and levofloxacin, respectively. Antibiotic resistance genes as tet $A$ gene were tested for isolated $E$. coli and detected by incidence rate of $91.18 \%$. qac resistance genes resembling as qacED1 and $q a c A / B$ genes were detected in isolated E. coli $70.6 \%$ and $14.7 \%$, respectively.

Conclusion: E. coli isolated from chickens in Egypt was carried qac and antibiotic-resistant genes that affect the poultry industry.

Keywords: antimicrobial resistance, chickens, Egypt, Escherichia coli, qac resistance genes.

\section{Introduction}

Avian pathogenic Escherichia coli (APEC) unlike other normal microflora $E$. coli in poultry intestine APEC spreads into several internal organs and causes systemic fatal disease colibacillosis, which is characterized by septicemia with multiple organ lesions, typically pericarditis, airsacculitis, perihepatitis, peritonitis, and other extra-intestinal lesions [1]. In poultry farms and surrounding environment, antibiotic resistance occurs frequently and can be spread to humans through food or water chain and also by routes such as environmental contamination by poultry waste and direct interaction with animals [2]. Quaternary ammonium compounds (QACs) are cationic surface

Copyright: Ibrahim, et al. Open Access. This article is distributed under the terms of the Creative Commons Attribution 4.0 International License (http://creativecommons.org/licenses/ by/4.0/), which permits unrestricted use, distribution, and reproduction in any medium, provided you give appropriate credit to the original author(s) and the source, provide a link to the Creative Commons license, and indicate if changes were made. The Creative Commons Public Domain Dedication waiver (http:// creativecommons.org/publicdomain/zero/1.0/) applies to the data made available in this article, unless otherwise stated. active detergents generally used for the control of microorganisms in clinical and industrial environments plus used in the disinfection of hard surfaces [3]. The last line of defense for the poultry industry could possibly be the use of disinfectants as QACs that are frequently used in environments where antibiotics are used, thus fuelling the concern of a relationship between QAC and antibiotic resistance [4]. QAC resistance genes frequently existed among $E$. coli isolates. The qac genes were highly associated with antimicrobial resistance phenotypes [5]. qac genes in Gram-negative bacteria were most frequently found in combination with genes coding for resistance to aminoglycosides, chloramphenicol, sulfonamides, trimethoprim, and $\beta$-lactams $[6,7]$. In the previous study, detection of the disinfectant resistant gene of aerobic bacteria in unhatched chicken eggs in Egypt was done, and the results indicate the presence of qacED1 gene in isolated E. coli with incidence rate of $100 \%$ [8].

The significance of study is to explain the failure of treatment of $E$. coli infection in poultry using antibiotics and increases the infection of E.coli during first week of age besides that the antibiotic resistance occurs 
often in poultry farms and surrounding environment which can be spread to humans via food or water chain.

Hence, the present investigation aimed to study the disinfectant and antibiotic resistance genes among E. coli isolated from chickens in Egypt.

\section{Materials and Methods}

\section{Ethical approval}

Ethical approval for this study was obtained from Animal Health Research Institute of Egypt.

\section{Collected samples}

Organs (liver, lung, heart, yolk sac, and bone marrow) of 1500 chicken samples were collected from diseased chickens suffered from colibacillosis with PM findings as CRD, diarrhea and omphalitis from different age-old and different governorates of Egypt as: Giza; 610 samples, EL-Bahira; 350 samples, Fayoum; 230 samples, El-Dakahlia; 160 samples, El-Ismalia; 120 samples, and El-Sharkia; 100 samples during 2015-2016 in winter seasons. These samples were labeled and transported immediately on ice to Reference laboratory for quality control on poultry production (RLQP). All samples were handled aseptically and examined microbiologically.

\section{Bacteriological examination}

Isolation of E. coli by conventional method [9]

Each pooled sample was transferred to buffered peptone water and incubated for $16-18 \mathrm{~h}$ at $37^{\circ} \mathrm{C}$. After selective enrichment, a loopful of the broth was inoculated on MacConkey agar and Eosin Methylene blue agar (Oxoid), then incubated aerobically in $37^{\circ} \mathrm{C}$ for $24 \mathrm{~h}$. Suspected E. coli colonies were purified and kept for further identification.

\section{Microscopic examination}

Gram's stain was prepared and used for examined suspected colonies as described by Cruickshank [10] for morphological study.

\section{Biochemical confirmation}

Suspected colonies were examined using different biochemical reaction including indole reaction, methyl red test, Voges-Proskauer test, citrate utilization test, catalase test, sugar fermentation test, oxidase test, triple sugar iron, and Christensen's urea agar test according to Quinn et al. [9].

\section{Serological identification}

E. coli isolates were serologically identified using rapid diagnostic E. coli antisera Set 1 containing polyvalent and monovalent O antisera (DENKASEIKEN Co. LTD, Japan) according to Edwards and Ewing [11].

\section{Antibiotic susceptibility testing}

Sensitivity to 12 different groups antibacterial drugs (Ampicillin $10 \mu \mathrm{g}$, Amoxicillin $10 \mu \mathrm{g}$, Gentamicin $10 \mu \mathrm{g}$, Streptomycin $10 \mu \mathrm{g}$, Erythromycin $15 \mu \mathrm{g}$, Amoxi-clavulanic acid 20/10 $\mu \mathrm{g}$, Doxycycline $30 \mu \mathrm{g}$, Tetracycline $30 \mu \mathrm{g}$, Nalidixic acid $30 \mu \mathrm{g}$, Levofloxacin $5 \mu \mathrm{g}$, Colistin sulfate $25 \mu \mathrm{g}$, and trimethoprim-sulfamethoxazole $1.25 / 23.75 \mu \mathrm{g}$ ) from Oxoid Hampshire, U K, was tested by disk diffusion method according to Quinn et al. [9] and Cruickshank [10]. The interpretation of the inhibition zones of tested culture was tested according to Clinical and Laboratory Standards Institute [12].

\section{Polymerase chain reaction (PCR) for the identifica-} tion of different genes

\section{Oligonucleotide primers}

Primers used were supplied from Metabion (Germany) and are listed in Table-1 [13-15], and cycle condition for different primers is shown in Table-2.

\section{DNA extraction}

DNA extraction from samples was performed using the QIAamp DNA Mini kit (Qiagen, Germany, $\mathrm{GmbH}$ ) with modifications from the manufacturer's recommendations.

\section{Results}

\section{Occurrence of $E$. coli in chickens}

$E$. coli isolates showed bright pink colonies, lactose fermentable on MacConkey agar plates and showed a distinctive metallic green sheen on EMB agar plates. Biochemically, all E. coli suspected isolates were lactose fermenting colonies, positive indole, methyl red, and catalase. Meanwhile all isolates were negative oxidase, urea hydrolysis, citrate utilization, Voges-Proskauer and didn't produce $\mathrm{H}_{2} \mathrm{~S}$.

The incidence of $E$. coli isolation in chicken was $34 \%$. The serotyping of isolated $E$. coli recovered from different organs of chickens revealed that 24 strains could be identified serologically. They belonged to 12 different serogroups. The most commonly detected E. coli serogroups isolated were $\mathrm{O} 128$ (4 isolates), O111 (3 isolates), O44 (3 isolates), O158 (2 isolates), O2 (2 isolates), O115 (2 isolates), O20 (2 isolates), O29, O15, O169, O125, O26 and O6, while 10 strains were not typed due to antiserum availability.

Table-1: Primers used for sequence of partial and complete fusion gene.

\begin{tabular}{|c|c|c|c|}
\hline Primer & Sequence & Amplified product & References \\
\hline qacED1 & $\begin{array}{l}\text { TAA GCC CTA CAC AAA TTG GGA GAT AT } \\
\text { GCC TCC GCA GCG ACT TCC ACG }\end{array}$ & 362 bp & [13] \\
\hline$q a c A / B$ & $\begin{array}{l}\text { GCAGAAAGTGCAGAGTTCG } \\
\text { CCAGTCCAATCATGCCTG }\end{array}$ & 361 bp & [14] \\
\hline $\operatorname{tet} A(A)$ & $\begin{array}{l}\text { GGTTCACTCGAACGACGTCA } \\
\text { CTGTCCGACAAGTTGCATGA }\end{array}$ & 576 bp & {$[15]$} \\
\hline
\end{tabular}




\section{Antibiogram pattern of isolated $E$. coli}

Antibiogram pattern of E. coli in our study revealed that $100 \%$ of the isolates were resistant to ampicillin, erythromycin, and sulfamethoxazole/trimethoprim, while E. coli isolates were sensitive for colistin sulfate and levofloxacin with $73.53 \%$ and $38.23 \%$ as shown in Table- 3 .

\section{Detection of the genes of isolated $E$. coli by conven- tional PCR}

Screening the presence of tetA, qacEDI and $q a c A / B$ genes by PCR technique after DNA extraction revealed that tet $A$ gene in $31(91.18 \%)$, qacED1 gene in $24(70.56 \%)$ and $q a c A / B$ gene in $5(14.7 \%)$ out of 34 tested E.coli isolates.

\section{Discussion}

Avian colibacillosis is an extraintestinal infection that can progress into several lesions in diverse organs as polyserositis, cellulitis, salpingitis, perihepatitis, peritonitis, septicemia, airsaculitis, and death. These cause harsh economic losses in the poultry industry, due to the significant number of morbidities, mortalities, slaughter condemnation, and reduced productivity of affected birds [16].

The incidence of $E$. coli isolation in chicken was $34 \%$ These results are agreed to some extent with that obtained by Ashraf et al. [17] who isolated E. coli in Egypt at $38 \%$.

The most commonly detected $E$. coli serogroups were O128, O111, O44, O158, and O2. E. coli serotypes had been previously isolated from chicken and newly hatched chicks in Egypt as reported by Ashraf et al. [17] who detected O78 and O111, El-Haleem [18] and Taha [19] detected O2, El-Jakee et al. [20] collected E. coli serogroups O2, O6, O8, O26, O27, O78, O86, O111, O128, O157, and O136 from chicken cloacal swabs, El-Sayed et al. [21] founded O111, O55, O142, and O128, El Jakee et al. [22] collected E. coli isolates serogroups O125:K70, O1:K-, O146:K-, O26:K-, O78:K80, O126:K58, and O128:K67 from diseased chickens to prepare a potent $E$. coli vaccine to control colibacillosis in chickens, and also Bakheet et al. [8] identified $\mathrm{O} 2: \mathrm{H} 6$ (2 isolates), O163:H2 (2 isolates), O128:H2 (3 isolates), O158 (2 isolates), and O44:H18 ( 2 isolates).

Antimicrobial resistance has become a worldwide problem, and the vast consumption of antibiotics by both humans and animals leads to the development and spread of a large number of antibiotic resistance among bacterial populations consequently creating critical public health problems. In the current study, isolated $E$. coli revealed that $100 \%$ of the isolates were resistant to ampicillin, erythromycin, and sulfamethoxazole/trimethoprim (each) as shown in Table-3 that results agreed with Subedi et al. [23] who showed that the maximum resistance of $50 \mathrm{E}$. coli strains to ampicillin (98\%), Bakheet et al. [8] who recorded resistant to sulfamethoxazole/trimethoprim $100 \%$, and Radwan et al. [24] who discussed that antibiogram profiles of E. coli isolates and indicated maximum resistance to ampicillin (100\%); furthermore, Eid et al. [25] reported that the highest resistance rates were recorded against trimethoprim sulfate, doxycycline, tetracycline, and amoxicillin $(94.1 \%, 93.2 \%$, $92.9 \%$, and $92.3 \%$, respectively). While E. coli isolates were sensitive for colistin sulfate and levofloxacin with the percentage of $73.53 \%$ and $38.23 \%$, respectively, Makhol et al. [26] found that $69.4 \%$ of $E$. coli isolates were sensitive to colistin sulfate.

Table-2: Cycling conditions of the different primers.

\begin{tabular}{|c|c|c|c|c|c|c|}
\hline Gene & $\begin{array}{c}\text { Primary } \\
\text { denaturation }\end{array}$ & $\begin{array}{c}\text { Secondary } \\
\text { denaturation }\end{array}$ & Annealing & Extension & $\begin{array}{c}\text { Number of } \\
\text { cycles }\end{array}$ & $\begin{array}{c}\text { Final } \\
\text { extension }\end{array}$ \\
\hline \multirow[t]{2}{*}{ QacED1 } & $94^{\circ} \mathrm{C}$ & $94^{\circ} \mathrm{C}$ & $58^{\circ} \mathrm{C}$ & $72^{\circ} \mathrm{C}$ & 35 & $72^{\circ} \mathrm{C}$ \\
\hline & $5 \mathrm{~min}$ & $30 \mathrm{~s}$ & $40 \mathrm{~s}$ & $40 \mathrm{~s}$ & & $7 \mathrm{~min}$ \\
\hline \multirow[t]{2}{*}{$Q a c A / B$} & & & $53^{\circ} \mathrm{C}$ & & & $72^{\circ} \mathrm{C}$ \\
\hline & & & $40 \mathrm{~s}$ & & & $7 \mathrm{~min}$ \\
\hline \multirow[t]{2}{*}{$\operatorname{Tet} A(A)$} & & & $50^{\circ} \mathrm{C}$ & & & $72^{\circ} \mathrm{C}$ \\
\hline & & & $40 \mathrm{~s}$ & & & $10 \mathrm{~min}$ \\
\hline
\end{tabular}

Table-3: Antibiotic resistance pattern of isolated E. coli.

\begin{tabular}{lccc}
\hline Antimicrobial agents & Resistance & Intermediate & Sensitive \\
\cline { 2 - 3 } & $\mathbf{n}(\%)$ & $\mathbf{n}(\%)$ & $\mathbf{n}(\%)$ \\
\hline Ampicillin & $34(100)$ & - & - \\
Amoxicillin & $33(97.06)$ & - & $1(2.94)$ \\
Gentamicin & $22(64.71)$ & $2(5.88)$ & $10(29.41)$ \\
Streptomycin & $33(97.06)$ & - & $1(2.94)$ \\
Erythromycin & $34(100)$ & - & - \\
Amoxicillin-clavulanic acid & $32(94.12)$ & - & $2(5.88)$ \\
Doxycycline & $30(88.24)$ & - & $4(11.76)$ \\
Tetracycline & $32(94.12)$ & - & $2(5.88)$ \\
Nalidixic acid & $30(88.24)$ & - & $4(11.76)$ \\
Levofloxacin & $9(26.47)$ & $12(35.29)$ & $13(38.23)$ \\
Colistin sulfate & $7(20.59)$ & $2(5.88)$ & $25(73.53)$ \\
Trimethoprim-sulfamethoxazole & $34(100)$ & - & - \\
\hline
\end{tabular}


The extensive and prolonged use of tetracycline in the poultry industry is undoubtedly one of the explanations for the high prevalence of resistance to tetracycline in broilers [27]. Concerning tetracycline resistance, in our study, E. coli isolates were $94.12 \%$ resistance to tetracycline antibiotics.

The tetA gene was tested for isolated E. coli to assess its resistance to tetracycline. Interestingly, the positive PCR percentage $(91.18 \%)$ was high as shown in isolates. However, the phenotypic antibiotic susceptibility test was $94.12 \%$, which may be related to more genes than tetA gene contributing for tetracycline resistance in E. coli. Sengeløv et al. [28] examined $E$. coli isolates from diseased and healthy broilers for the presence of tetracycline resistance genes tet $(A),(B),(C),(D)$, or $(E)$ and found that the tet $A$ and tet $B$ were the most prevalent; in isolates from healthy broilers, tet $A$ was present in $41.2 \%$, tet $B$ in $52.9 \%$, and tetD in $5.9 \%$, and in isolates originated from diseased broilers, tet $A$ was present in $72.2 \%$ and tet $B$ in $27.8 \%$ samples. Furthermore, Abo-Amer et al. [29] recorded that tetracyclines genes tet $A$ and tet $B$ were observed at the prevalence of $65 \%$ among $E$. coli isolated from chicken farms in Saudi. There was a correlation between the presence of integrons and resistance to tetracycline in chicken $E$. coli isolates from the Veterinary Antimicrobial Resistance Surveillance Network [30].

QACs are cationic surface active detergents extensively used in the poultry industry as of their low relative toxicity, good antibacterial properties non-irritating, non-corrosive, low toxicity, and reasonably effective in the presence of organic matter. Hence, it makes a disinfectant of choice for equipment such as incubators and hatching trays [31]. Genes that confer resistance to QACs are qacE and qacED1; qacED1 a mutant version of $q a c E$ appears to be partially functional as a multidrug transporter and is widely distributed throughout Gram-negative bacteria due to its location on the $3^{\prime}$ conserved region of class 1 integrons [32].

In this study, the qacED1 gene was reported in $70.6 \%$ E. coli (24 positive samples from 43 $E$. coli isolates). These results were nearly in accordance with Amira [33] and El Tawab et al. [34] who found qacEDl gene among $E$. coli isolates (93.1\% and $63.16 \%$, respectively) in Egypt. QacE gene (including its attenuated variant qacED1) is widely spread in Gram-negative bacteria, mainly in Enterobacteriaceae [35,36].

$Q a c A / B$ gene was founded in $14.7 \% \mathrm{E}$. coli in our study; nevertheless, $q a c A / B$ was founded in Gram-negative bacteria like E. coli. It seems that the presence of the qac genes does not necessarily imply increased resistance to antiseptics that could be relevant for practice [37].

Antimicrobial resistance has become a worldwide problem, and the massive usage of antibiotics by both humans and animals leads to the development and spread of a large number of antibiotic resistance among bacterial populations consequently creating critical public health problems. The co-resistance of QAC and antibiotics could be attained by linkage of different resistance mechanisms on the similar plasmid, transposon otherwise integrin, or any combination of these [4]. The localization of these QAC determinants on different mobile elements may share in the transmission of resistance to the other bacteria [38]. Among Gram-negative bacteria, the qac genes are often related with plasmid-mediated class 1 integrons which harbor a diversity of antibiotic resistance genes [7].

\section{Conclusion}

E. coli is one of the most dangerous pathogens that threaten the poultry industry in Egypt due to the high rate of its presence in the farms as well as the presence of the qac resistance gene and antibiotic resistance gene in E. coli definite a link between antibiotic and disinfectant in possible that needs further study.

\section{Authors' Contributions}

The study was designed by SAM, SAN, and JKE. WAI and AME did the molecular work. Data collection, analysis and manuscript preparation by WAI. All authors read and approved the final manuscript.

\section{Acknowledgments}

We are grateful to the Reference Laboratory for Veterinary Quality Control on Poultry Production, Animal Health Research Institute, Egypt, for the technical support. There was no specific fund received for this study.

\section{Competing Interests}

The authors declare that they have no competing interests.

\section{Publisher's Note}

Veterinary World remains neutral with regard to jurisdictional claims in published institutional affiliation.

\section{References}

1. Oh, J.Y., Kang, M.S., Kim, J.M., An, B.K., Song, E.A., Kim, J.Y. and Kwon, Y.K. (2011) Characterization of Escherichia coli isolates from laying hens with colibacillosis on 2 commercial egg-producing farms in Korea. Poult. Sci., 90(9): 1948-1954.

2. Velhner, M., Petrović, J., Stojanov, I., Ratajac, R. and Stojanović, D. (2010) Mechanisms transmission of resistance to bacteria. Arch. Vet. Med., 3(1): 85-92.

3. Ioannou, C.J., Hanlon, G.W. and Denyer, S.P. (2007) Action of disinfectant quaternary ammonium compounds against Staphylococcus aureus. Antimicrob Agents Chemother, 51(1): 296-306.

4. Hegstad, K., Langsrud, S., Lunestad, B.T., Scheie, A.A., Sunde, M. and Yazdankhah, S.P. (2010) Does the wide use of quaternary ammonium compounds enhance the selection and spread of antimicrobial resistance and thus threaten our health? Microb. Drug Resist., 16(2): 91-104.

5. Zhang, A., He, X., Meng, Y., Guo, L., Long, M., Yu, H. 
and Zou, L. (2016) Antibiotic and disinfectant resistance of Escherichia coli isolated from retail meats in Sichuan, China. Microb. Drug Resist., 22(1): 80-87.

6. Colinon, C., Jocktane, D., Brothier, E., Rossolini, G.M., Cournoyer, B. and Nazaret, S. (2010) Genetic analyses of Pseudomonas aeruginosa isolated from healthy captive snakes: Evidence of high inter-and intrasite dissemination and occurrence of antibiotic resistance genes. Environ. Microbiol., 12(3): 716-729.

7. Zhao, W.H., Chen, G., Ito, R., Kimura, S. and Hu, Z.Q. (2012) Identification of a plasmid-borne blaIMP-11 gene in clinical isolates of Escherichia coli and Klebsiella pneumoniae. J. Med. Microbiol., 61(2): 246-251.

8. Bakheet, A.A., Naglaa, M.A., Sayed, Al Habaty and Soad, A.N. (2017) Detection of Disinfectant resistant aerobic bacteria in unhatched chicken eggs. Benha Vet. Med. J., 32(2): 248-259.

9. Quinn, J.P., Carter, M.E., Markey, B.K. and Carter, G.R. (2002) Clinical Veterinary Microbiology. $4^{\text {th }}$ ed. Harcourt Publishers Ltd., London, UK. p61-63.

10. Cruickshank, R. (1975) Medical Microbiology. In: The Practice of Medical Microbiology. Vol. 2. Churchill Livingstone, Edinburgh.

11. Edwards, R. and Ewing, H. (1972) Identification of Enterobacteriaceae. Burgess Publishing Co., Minneapolis. p709.

12. Clinical and Laboratory Standards Institute. (2015) Performance Standards for Antimicrobial Susceptibility Testing; Twenty-First Informational Supplement. Vol. 31. Clinical and Laboratory Standards Institute, Wayne, PA, USA. p42-46.

13. Chuanchuen, R., Khemtong, S. and Padungtod, P. (2007) Occurrence of qacE/qacED1 genes and their correlation with class 1 integrons in Salmonella Enterica isolates from poultry and swine. Southeast Asian J. Trop. Med. Public Health, 38(5): 855-862.

14. Noguchi, N., Suwa, J., Narui, K., Sasatsu, M., Ito, T., Hiramatsu, K. and Song, J.H. (2005) Susceptibilities to antiseptic agents and distribution of antiseptic-resistance genes $q a c A / B$ and $s m r$ of methicillin-resistant Staphylococcus aureus isolated in Asia during 1998 and 1999. J. Med. Microbiol., 54(6): 557-565.

15. Randall, L.P., Cooles, S.W., Osborn, M.K., Piddock, L.J.V. and Woodward, M.J. (2004) Antibiotic resistance genes, integrons and multiple antibiotic resistance in thirty-five serotypes of Salmonella Enterica isolated from humans and animals in the UK. J. Antimicrob. Chemother, 53(2): 208-216.

16. Dho-Moulin, M. and Fairbrother, J.M. (1999) Avian pathogenic Escherichia coli (APEC). Vet. Res., 30(2-3): 299-316.

17. Ashraf, A.A., Ahmed, A.A., Samir, A.A., Fatma, I.E. and Emad, E.A. (2014) Detection of some virulence genes of avian pathogenic E. coli by polymerase chain reaction. Benha Vet. Med. J., 26(2): 159-176.

18. El-Haleem, Y.F.A. (2000) Some Epidemiological Studies on Escherichia coli in Poultry Farms. M. V. Sc. Thesis, Faculty of Veterinary Medicine, Zagazig University, Egypt.

19. Taha, N.A.A. (2002) Zoonotic Importance of enteropathogenic E.coli (EPEC). Ph. D.Thesis, Faculty of Veterinary Medicine, Zagazig University, Egypt.

20. El-Jakee, J.K., Mahmoud, R.M., Samy, A.A., El-Shabrawy, M.A., Effat, M.M. and Gad El-Said, W.A. (2012) Molecular characterization of E. coli isolated from chicken, cattle and buffaloes. Int. J. Microbiol. Res., 3(1): 64-74.

21. El-Sayed, M.E., Shabana, I.I., Esawy, A.M. and Rashed, A.M. (2015) Detection of virulence-associated genes of avian pathogenic Escherichia Coli (APEC) isolated from broilers. J. Genet., 1(1): 4.

22. El Jakee, J.K., El Amry, G.M., Hessain, A.M., Hemeg, H.A., Shafei, S.M. and Moussa, I.M. (2016) The production and evaluation of autogenous vaccine against avian colibacillosis. J. Anim. Plant Sci., 26(1): 79-87.

23. Subedi, M., Luitel, H., Devkota, B., Bhattarai, R.K., Phuyal, S., Panthi, P. and Chaudhary, D.K. (2018) Antibiotic resistance pattern and virulence genes content in avian pathogenic Escherichia coli (APEC) from broiler chickens in Chitwan, Nepal. BMC Vet. Res., 14(1): 113.

24. Radwan, I.A.E., Salam, H.S.H., Abd-Alwanis, A.A. and Al-Sayed, M.Y. (2014) Frequency of some virulence-associated genes among multidrug-resistant Escherichia coli isolated from septicemic broiler chicken. Int. J. Adv. Res. 2(12):867-874

25. Eid, S.E.A., Nasef, S.A. and Erfan, A.M. (2015) Characterization of E. coli associated with high mortality of poultry flocks. Assiut Vet. Med. J., 59(139): 51-61.

26. Makhol, B.M., Habreh, N. and Sakural, K. (2011) Antibiotic resistance of E. coli isolated from poultry in Syria. Assiut Vet. Med. J., 57(128): 265-275.

27. Van den Bogaard, A.E., London, N., Driessen, C.A.G. and Stobberingh, E.E. (2001) Antibiotic resistance of faecal Escherichia coli in poultry, poultry farmers and poultry slaughterers. J. Antimicrob. Chemother., 47(6): 763-771.

28. Sengeløv, G., Halling-Sørensen, B. and Aarestrup, F.M. (2003) Susceptibility of Escherichia coli and Enterococcus faecium isolated from pigs and broiler chickens to tetracycline degradation products and distribution of tetracycline resistance determinants in E. coli from food animals. Vet. Microbiol., 95(1-2): 91-101.

29. Abo-Amer, A.E., Shobrak, M.Y. and Altalhi, A.D. (2018) Isolation and antimicrobial resistance among Escherichia coli isolated from farm chickens in Taif, Saudi Arabia. $J$. Glob. Antimicrob. Resist.,15: 65-68.

30. Marchant, M., Vinué, L., Torres, C. and Moreno, M.A. (2013) Change of integrons over time in Escherichia coli isolates recovered from healthy pigs and chickens. Vet. Microbiol., 163(1-2): 124-132.

31. Haynes, R.L. and Smith, T.W. (2003) Hatchery Management Guide for Game Birds and Small Poultry Flock Owners. Online Publication of Mississippi State University. Available from: http://www.extension.msstate.edu/content/ hatchery-management-guide-for-game-bird-and-smallpoultry-flock-owners.

32. Kazama, H., Hamashima, H., Sasatsu, M. and Arai, T. (1999) Characterization of the antiseptic-resistance gene qacE delta 1 isolated from clinical and environmental isolates of Vibrio parahaemolyticus and Vibrio cholerae nonO1. FEMS Microbiol. Lett., 174(2): 379-384.

33. Amira, F.A. (2016) Molecular Characterization of Virulence Genes in Salmonella spp. isolated from Poultry. Ph.D. Thesis, Kafrelsheikh University.

34. El Tawab, A.S.A., Soad, A.N., Fatma, I.E. and Ola, A.I. (2017) Prevalence of eaeA and qacEAl genes in Escherichia coli isolated from omphalitis in baby chicks. Benha Vet. Med. J., 32(1): 184-192.

35. Wang, C., Zhan, Q., Mi, Z., Huang, Z. and Chen, G. (2008) Distribution of the antiseptic-resistance gene qacEAl in 283 clinical isolates of Gram-negative bacteria in China. $J$. Hosp. Infect., 69(4): 394-396.

36. Mak, J.K., Kim, M.J., Pham, J., Tapsall, J. and White, P.A. (2008) Antibiotic resistance determinants in nosocomial strains of multidrug-resistant Acinetobacter baumannii. $J$. Antimicrob. Chemother., 63(1): 47-54.

37. Jaglic, Z. and Cervinkova, D. (2012) Genetic basis of resistance to quaternary ammonium compounds--the qac genes and their role: A review. Vet. Med., 57(6): 275-281.

38. Gillings, M.R., Xuejun, D., Hardwick, S.A., Holley, M.P. and Stokes, H.W. (2009) Gene cassettes encoding resistance to quaternary ammonium compounds: A role in the origin of clinical class 1 integrons? ISME J., 3(2): 209. 